\title{
The Three-Five-Eight (Bachelor, Master, Doctorate) System: An Essential and Demanding Reform for the University of Abomey-Calavi, Benin (West Africa)
}

\author{
Prudence Sylviane Djidjoho Mignanwande*, Jean-Claude Hounmenou \\ Department of Psychology and Educational Sciences, University of Abomey-Calavi, Abomey-Calavi, Benin \\ Email: * prudencesylviane@yahoo.fr
}

How to cite this paper: Mignanwande, P.S.D. and Hounmenou, J.-C. (2016) The Three-Five-Eight (Bachelor, Master, Doctorate) System: An Essential and Demanding Reform for the University of Abomey-Calavi, Benin (West Africa). Open Journal of Social Sciences, 4, 158-170.

http://dx.doi.org/10.4236/jss.2016.49014

Received: August 5, 2016

Accepted: September 19, 2016

Published: September 22, 2016

Copyright $\odot 2016$ by authors and Scientific Research Publishing Inc. This work is licensed under the Creative Commons Attribution International License (CC BY 4.0).

http://creativecommons.org/licenses/by/4.0/ (c) (i) Open Access

\begin{abstract}
Nowadays, universities are undergoing profound changes in order to adapt their educational contents to the requirements of the world of employment. Thus, the establishment of a new system of certification and classification of qualifications has emerged through the Bachelor, Master, Doctorate called "Licence Master and Doctorat" (LMD) reform in French speaking countries. This research aims to show that the implementation of the LMD system is an imperative for the University of Abomey-Calavi. On the methodological side, we conducted both descriptive and analytical study based on the principle of triangulation. The data used for this study come from two main tools: survey questionnaire and interviews grid supported by literature review. This research was conducted on a sample of 690 individuals selected by random and purposive method. It came out from our investigations that LMD system relies on fundamental principles that are not yet mastered and applied by the different actors of the University of Abomey-Calavi. Consequently, 65.33\% expressed their qualifications are not recognized as such in other universities or countries. Our results also indicate that $73.39 \%$ of the students have not received information about the possibility offered by the LMD system to complete their education within the same institution or another institution through principle of mobility. Students surveyed on the question of capitalization of knowledge through transferable and capitalized education credits recognized in a proportion of $59.82 \%$ they have no information on this vital principle of the LMD reform. Thus, it is important to rethink the system, reframe and adapt its principles and requirements to local realities.
\end{abstract}

\section{Keywords}

LMD Reform, Requirements, Principles, UAC 


\section{Introduction}

The various crises experienced by education systems at all levels and across the African continent have forced policymakers to adapt the curricula of learning program to the context of the current globalization. Several countries have therefore engaged in modernization policies of higher education systems and programs in this case the LMD reform. The implementation of this reform has resulted in Europe with the signing by 29 European countries in Bologna in Italy of a joint statement June 19, 1999. This statement aims to create a European area of higher education and boost its promotion globally [1], to restore the attractiveness of European universities and support them in the competition between them and their US counterparts. To achieve this, these countries have reorganized and harmonized their higher education architecture through the adoption of the LMD reform.

Francophone African universities whose education system is oriented on that of France did not remain on the sidelines of these reforms. Then in July 2005, university officials from Benin, Burkina Faso and Togo have volunteered to commit together in this reform [2]. It was therefore necessary to find an adequate framework to merge the efforts so that these universities can truly and properly align with the Bologna Declaration. Thus the Network for Excellence in Higher Education in West Africa (REESAO) was born October 11, 2005 with the seven national universities of Benin, Burkina Faso and Togo. Today, this network consists of fourteen (14) universities and centers of higher education from these seven (07) countries and aims to promote a new policy of interuniversity cooperation to facilitate mobility and employability and popularize the use of information and communications technology for learning purposes [3].

The magnitude of the requirements and challenges in the implementation of the LMD reform, although contrasting with these very positive speech to the integration of that reform in our universities leads us to ask ourselves the following question: in the current state and after a decade of implementation of the LMD reform, the cardinal principles of the LMD system i.e. "teach differently, study differently, evaluate differently, manage differently and professionalize" are effective in public universities in the Republic of Benin and particularly the University of Abomey-Calavi?

\section{Clarification of Concepts}

\subsection{The LMD System}

The LMD is an acronym for Licence, Master, Doctorate. The LMD system represents a set of changes and innovations introduced in higher education consisting of an organization into three levels of training system: the License (bachelor), Master and Doctorate. The Master Licence Doctorate (LMD) or 3-5-8 system is implemented through the "Bologna process" which refers to the European harmonization of higher education. The ministers in charge of higher education in France, Germany, the United Kingdom and Italy assembled at the Sorbonne in France, made a joint declaration to harmonize the architecture of the European system Higher Education. The LMD system is therefore, an important element in the process of renewal of content and teaching practices 
in universities. This harmonization of the system of higher education aimed to facilitate progressive policies and to promote the international mobility of students is based on a reorganization of training offerings [4]. This reorganization makes this system a real reform.

\subsection{Reform}

The Grand Larousse defines reform as "an important and radical change in an institution for the purpose of improvement". Champy and Étévé cited by Houessou [5] specify that "reform is a major and deliberate change (considered desirable) from an initial state to a projected state".

Etymologically, the word reform comes from latin "reformare" which means reconstitute or train again. In other words, it is a change in the institutional or social organization of a country or a sector of activity in order to make improvements. In the educational field, reform is a change in the current curriculum or the improvement of training opportunities by the integration of new knowledge or skills. The current LMD reform offers the facility to actors from higher education system to move within their network [3].

\subsection{Mobility}

According to the Petit Robert, mobility comes from latin "mobilitas" which means move; It is the nature of which may move or be driven, changed place or position. The grand Larousse states that it is "facility to move, to be in motion, to change, to move". Under the LMD system, mobility is the possibility for the learners to go from one institution to another, from one university to another or to change course while keeping his academic credits already validated. It also concerns the teachers-researchers. By the way, This is what defends the African and Malagasy Council for Higher Education because according to this institution, "the promotion of mobility of students, teachers, researchers and other university staff is one of the most important components of the LMD reform" [5]. To do this, the entire university community should mobilize to remove the obstacles to freedom of movement of students, teachers, researchers and other university staff [6]. In Benin, this mobility is supported by article 2 in its paragraphs 2 and 5 of Decree No. 2010-272, June 11, 2010 adopting the LMD system in higher education.

\section{The Fundamentals for the Emergence of the LMD System}

Many thoughts and questions have arisen from the accelerated crisis of higher education system in African universities and inconsistencies of scientific research policies [7] Indeed, it is from the 1990s that several thoughts and publications have been completed at the national, regional and international level to define strategies for revitalization of the higher education. This is actually in the wake that was held in Paris in 1998, the World Conference on Higher Education (CMES), which brought together over four thousand participants. This conference was an opportunity for stakeholders and part- 
ners of higher education (ministries, responsibles for education and higher education, teachers, researchers, students, parliamentarians, representatives of intergovernmental and non-governmental organizations, the world of economy, funding agencies, houses of edition ...) to diagnose the evils with which it was confronted and propose solutions to end the crisis [8].

Nevertheless, around the world, it is recognized that universities, by the unique place they occupy in the production of new knowledges, their transmission and their ownership, through education and training, their dissemination and valorization are essential and indispensable vehicles for economic and social development of nations. Thus understood, the current trend has made the university an important pillar for the accession to the social welfare. It is in this sense that Djadji [9] argued that to get out of under-development; the safest route is higher education with research tailored to the needs of populations. However, in 1962 already the UNESCO, in cooperation with the Economic Commission for Africa, at the Tananarive conference on the future of higher education in Africa, has called to African universities on their fate through two major challenges [10].

Thus, the role of African higher education in the cultural, social and economic development of the continent has become increasingly indisputable. Therefore, the choice of programs of higher education and their adaptation to the terms and conditions of life and African developments, for economic development, public administration, natural resources and African Studies, is delicate, in short, its adaptability to the realities as much national and international, but also and especially the only ability to respond.

However, to get there, unprecedented mutations must operate within high education system. Benin which has realized the need to undertake reform of its higher education system, like other African countries, was hired in this way in order to find solutions to the university problems [11]. Thus, several reform such as were undertaken in education. A decade after the adoption of the LMD system, we present below the main axes.

\section{The Main Axes of the LMD System}

The LMD system is essentially based on two axes: the capitalization and the semestrialisation.

\subsection{The Capitalization as Pedagogical Axis}

Capitalization is one of the main principles underpinning the LMD reform, lt's final acquisition of teachings units. In other words, the capitalization of experience allows the learner to keep valid credits for life "even if he changes course or institution" [5]. In fact, in higher education in Europe, this system is called "European credit system ECTS or European Credit Transfer System". These credits have a numerical value that ranges from 01 to 60 and is allocated to each unit of course corresponding to the total workload (lectures, internships, memory thesis, etc and work of the student) required for the student to achieve the EU objectives.

Under the LMD system, 60 credits represent the volume of a year of academic study. 
Thus, generally a credit is between 20 - 25 hours on average [3].

On the other hand, it's important to indicate that in context LMD, the notion of 'credit' has several characteristics. Therefore, it is both capitalizable, transferable and applicable to the whole of the work of the student. Indeed, the credit is capitalizable when its validation is definitively acquired regardless of the duration of the course [3]. On the other hand, it is said transferable when it's content remains the same, regardless of the selected route. Moreover, this system also allows validation of periods of studies abroad. Finally, as mentioned, it takes into account all activities and forms of education of the student.

The institutions have also the opportunity to choose different types of Educational Unit (EU) according to their training needs; however any offer training in general has four broad categories of EU: fundamental EU corresponding to the teachings that all students must take; Optional EU reserved for some students (deepening and professionalization); the cross-cutting EU (lessons designed to give tools to students from various sources: language, computer, mathematics, human rights, cultural and sports, etc.). In the course of the students, are also provided free EU (EU and the student freely chooses according to its liking and its needs). Thus, the student can therefore be formed by selecting the most relevant content to their profile and objectives, and time that suits him. This greatly increases its chances of success in semester. In principle, each semester require 30 credits: license $=180$ credits; Master $=120$ credits; $\mathrm{PhD}=180$ credits [3] [4]. What then of the semestrialisation in LMD context?

\subsection{The Semestrialisation as Institutional Axis}

The application of the LMD system requires that any University opts for a uniform presentation of training system: curriculum studies, duration of semesters, minimum hourly volume of a unit, entitled graduates. This institutional response allows the learner not be blocked in one type of training. In other words, all the training offered by the University is at its disposal to enable it to establish its own course. For flexibility of training pathways to be effective, it is necessary that all the all curricula fits in a relatively homogeneous framework different from the old system because according to the [4]. "one of the fundamental principles of the implementation of the LMD is the semestrialisation of programs and their organization into units of teachings. This formula replaces an annualized organization". Thus, the educational organisation is usually six-monthly. However, it is not superfluous to specify that in the LMD system, there are three (03) training courses which correspond to the three (03) grades defined by the reform: the Licence course-Master course- $\mathrm{PhD}$ course. A training course is then formed by a suite of teaching semesters divided as follows: six (06) semesters for the Licence, four (04) semesters for the Master and six (06) semesters for PhD. A teaching semester includes several training offerings; These in turn also includes Teaching Units (UE). The UE is in the form of course magisterial (CM), work tutorials (TD), work practices (TP), internships, thesis, etc. For each reference, a course-type (as defined by the University) is proposed. Nevertheless, accompanied by training team, the student 
may develop its own course [2]-[5] [11].

More and generally, a semester includes: fixed a number of weeks teaching and assessments. One academic year of two (02) semesters has about 38 to 40 weeks. This equals according to the same authors an annual workload of about 1500 to 1800 hours. The sub regional body explains and indicates that the academic year average 14 to 16 weeks for each semester [3]. It is therefore understandable that the new reform in academia is very demanding as to its application.

\section{The Requirements of the LMD System}

According to the organization of the training, the LMD reform learner requires a form of autonomy in all their actions. First, the learner begins basic university studies, i.e. the rank of license with a clear professional project, it must be able to develop by itself, and the ability to give him the training course which will lead to the realization of this professional project. It is "the linchpin of his university course and founded by extension orientation and trajectory to be followed by his studies [12] [13]". Then, he takes decisions throughout their training process: choose such or such teaching unit, completing his training, get back to level, restream, change University or even countries, etc. because "the school can no longer teach everything he needs in his life". He needs learn to learn; so, for the fundamental disciplines, It is necessary for him to take in charge" [14] [16]. Finally, it must be able to take advantage of all resources at its disposal to develop the best possible: human resources (teachers and academic advisors), information resources (handouts, libraries and online databases), time management etc. It must also persevere throughout this journey, keeping a clear and realistic view of the end of his training: professional integration in the best possible conditions.

To succeed in LMD, he must learn to manage his time, prepare to take multiple pathways for learning beginning by working from the first hour of instruction. Moreover, this success requires also deep changes on plan of curriculum, teaching practices and learning. In this regard, according to Colet et Berthiaume cited par Houessou, "the challenge of quality through substantial changes in its curriculum and teaching practices improved, notably by the introduction of new pedagogical approaches or the use of learning models adapted [5]".

In sum, the various requirements outlined in LMD concede learners the opportunity to receive a good offers of training. According to the ADEA/REESAO, a good offers of training is characterized by the:

1) Clear and legible path: all learners must be able to understand the objectives and components of a course. Generally, any person wishing to have information (parents, employers, adult on-the-job for example) must be able to understand the offers of a university institution. With regard to mobility, the course must also be readable for other institutions of education in the world;

2) Diversified courses: they allow the consideration of the diversity of university public and the progressive orientation of the student; They also give the opportunity to develop cross-cutting competences; 
3) Professionalizing course: as students progress, they can grab the convergences between training and their professional projects;

4) Realistic course: proposed course reflect the academic context (existing skills, working conditions) but with the job market, while giving students the means of mobility in a wider area than their own country [2].

\section{The University of Abomey-Calavi as Socio-Pedagogical Research Target}

The University of Abomey-Calavi is administratively located on the territory of the commune of Abomey-Calavi. It is one of the public institutions of higher education and research in Benin. It's the first University of Benin and the largest in terms of numbers of students, teachers-researchers, training institutions and training courses. Founded in 1970, the University of Abomey-Calavi (UAC) was born on the ashes of the higher Institute of Dahomey (former Benin) created in 1962. Called first, University of Dahomey (UD), she became in 1975 Université Nationale du Bénin (UNB) and will keep this name until in 2001, year of the creation of the second public University in Benin: the University of Parakou through the Decree $\mathrm{N}^{\circ}$ 2001-305 dated September 18, 2001. It is governed by two fundamental texts. It comes to ministerial orders No. 091-2009/MESRS/DC/SGM/SP of 15 April 2009 on the responsibilities, organization and functioning of the University of Abomey-Calavi, then No. 092-2009/MESRS/DC/SGM/R-UAC/SP-C of 15 April 2009 laying functions, organizations, and operation of the Rectorate of the University of $\mathrm{Ab}$ omey-Calavi. It is headed by a rector assisted by three vices elected and appointed by Council of Ministers Decree. These latter provide his interim in case of absence; each with clearly defined powers.

These provide its interim when absent; each of them having many assignments. In addition to a General Secretary and an accountant who assist the rectoral team, several administrative services support the rectorate in the discharge of its functions. Elected for a three-year term, the rector is the head of the executive body of the university. Its missions are to conduct administrative business, academic, educational, financial, social and political of the university [11] [15] [16].

The investigation focusing on the theme "the LMD system: essential and demanding reform" therefore covered under the tutelage of the University of Abomey-Calavi schools and faculties in Porto Novo, Lokossa and Abomey-Calavi. In detail, these are: classical faculties draining a significant number of students (Faculty of Letters Arts and Humanities Sciences, Faculty of Science and Technology, Faculty of Law and Political Science, Faculty of Economics and management; Faculty of agronomic Sciences and the Faculty of Health Sciences); schools and institute of professional education and training; administrative management structures of these centres and faculties [11] [15].

\section{Methodological Postures}

In this section, we define the objectives, the research assumptions and sampling. We also present the different instruments used to conduct this study. 


\subsection{Research Objectives}

The general objective of this research aims to show how the LMD system is a reform both demanding and essential for the UAC.

Specifically, it is to:

Present the foundations leading to the implementation of the LMD system.

Describe the main axes and the LMD reform requirements;

Appreciate if the conditions are met for a good implementation of the LMD to the UAC.

\subsection{Research Assumptions}

The new orientations of the current job market oblige the University of Abomey-Calavi to operate profound changes to ensure its effectiveness internally and externally.

Specifically, the reform implemented in the UAC is based on well-defined principles and foundations; the strict application of the LMD system requires the satisfaction of a few preconditions by the UAC.

\subsection{Sampling}

The sample used in this research was composed of all stakeholders from university primarily students who are the main beneficiaries of the reform LMD at UAC. As shown in Table 1, this sample is both random and reasoned and consists of 560 students in various academic centers of the former University of Abomey-Calavi. To triangulate the responses of the students about their experiences, 100 parents were interviewed at random. This brings the quantitative sample to 660 individuals. At the institutional level, actors working in the structures of the university administration and institutional actors of the labor market, are interviewed. Here, 30 actors were interviewed. Among these include both the administrative authorities of private institutions of higher education.

It should be noted that among the students contacted, there on 560 surveyed students, 402 either $17.78 \%$ are male and $15828.21 \%$ are female. Similarly, 58.92\% of students are aged 21 to 25; 28.75\% were aged between 16 and 20 . Students aged between 26 and 30 are among 65 either $11.60 \%$. Only 3 students $(0.53 \%)$ have an age between 31 to 35 years and $1(0.2 \%)$ has more than 35 years.

\subsection{The Instruments Deployed for Research}

In this research, two types of questionnaire were carefully designed from May 15 to May 30, 2015. Thus, a questionnaire is sent to students of different academic centers targeted. Parents of students are not concealed. An interview guide was designed to approach the actors of the university system and the employment market institutions.

How are then developed questionnaires?

In general, questionnaires have kept the same frame. Indeed, an introductory note is listed at the beginning of the issues to the attention of the respondents. It includes the context of administration of the questionnaire, the targeted objectives and the strategy 
Table 1. Summary of the sample.

\begin{tabular}{ccc}
\hline Target population & Number & Percentage \\
\hline Students & 560 & 81.16 \\
Parents of students & 100 & 14.49 \\
Resource persons & 30 & 4.35 \\
Total & 690 & 100.00 \\
\hline
\end{tabular}

of the filling of the questionnaire even in the absence of the investigator. The questionnaire includes three (03) components: the anamnestic information, knowledge of the foundations of the LMD reform, the LMD reform requirements. Addressing the anamnestic section, they relate to the General identification of the respondent. Moreover, the section relating to the requirements of the LMD reform, has allowed to go to the discovery of the different requirements and axes of the LMD system as well as the availability of the University of Abomey-Calavi to implementation the major principles underlying the implementation of the Bologna process.

\section{Results and Discussion}

\subsection{Process of Adoption of the LMD System}

The achievement of the Millennium Development Goals (OMD) requires a strong involvement of all socio-economic strata and political. To this end, the contribution of the University is therefore be both decisive and significant according to the UN. Thus, the role and the place of the University is no longer showing in this process because "Today it is no longer possible to initiate development of comprehensive policies without involving higher education" [4]. In this era of globalization and globalization, priority is much more given to the market economy, but public universities seem to no longer ensure opportunities for their graduates because the incoming flow that increase at the point of wanting to stifle the institution itself [4]. That is why logically, "The new reality of the global economy and the labor market leads to a wave of reconstruction and reconfiguration of training programs including disciplinary and methodological boundaries are being challenged" (Ndior, 2013, p.258). The University of Abomey is not also remained on the sidelines of this global reform wave. So, universities in the French-speaking states decided to unify under the REESAO through Directive $n^{\circ}$ 03/2007/CM/UEMOA. Ndior [13], in a study conducted in Senegal explains that "In fact the main reason is that we have no choice. The LMD is a global reform which is imposed on all countries". Therefore, the international character of the reform remains one of the motives that led universities to implement the LMD as "first it is to get in tune with what is going on elsewhere and avoid the African University outside. Many universities have adopted reform and the University of Dakar must not make an exception to the rule" [13]. Similarly, "in France, the reform is perceived as inevitable", "it falls on our heads", "we must make do", "no choice", "This is a reform like all the other" [4]. This fatality feeling is explained by the absence of some flexibility may allow 
each university, subregion or region to internalize the reform.

In the specific case of the University of Abomey-Calavi, it's "Since 2006, we started in the University curriculum the LMD: licence $(\mathrm{BAC}+3)$, the master $(\mathrm{BAC}+5)$ and doctoral degree $(\mathrm{BAC}+8)[\cdots]$. The challenge was that all French universities adopt the system from 2002 to 2010 " said a teacher. The LMD reform had its generalization phase from the academic year 2010 in the Republic of Benin [11].

In the other West African universities in the sub-region, one of the priorities is "[2] To make the generalization of the LMD in 2011 in all West African universities". Membership in the European project is obvious and reaffirmed by the CAMES. So by adopting the LMD, it is hoped to be part of a global trend "said another resource person encountered". It therefore urgent to appropriate the different principles underlying the implementation of that reform.

\subsection{The Legibility of Diplomas}

Regarding to the principles of the system LMD, the legibility of diplomas awarded by the University is one of the benefits resulting from the implementation of the LMD reform. This principle "provides better legibility and rank harmonization internationally. The corollary of this system is of course the culture of evaluation, the requirements of relevance and quality, participative management, the primacy of the professionalization and recognition of higher education as a driver of any development". For this purpose, different targets were interviewed on the principle of the legibility of the diplomas awarded in context LMD. On this issue, on the 560 surveyed students, 366 or $65.33 \%$ felt that their degrees are not recognized as such in other universities or countries when 194 or $34.67 \%$ of the students thought otherwise. The words of one of the resource persons confirm these proportions: "we say that we are in the LMD since 2007-2008, but the licence of FASEG is not even recognized in Canada; However we are talking about standardization of graduates as advantages of the LMD". In other words, the principle of the legibility of qualifications required by the LMD reform is not yet a reality. What about mobility in the LMD context?

\subsection{Knowledge on the Principle of Mobility in the LMD Context}

The question of the principle of mobility in context LMD has been studied in this investigation. According to the results collected, $73.39 \%$ of students said that they have not received information about the possibility that offers them the LMD system to complete their training within a same institution or from one institution to another. On the other hand, $26.61 \%$ of this target were said be sensitized on the principle of mobility. Contrary to students, $40.14 \%$ parents stated that the diplomas awarded in context LMD are accepted as such in other universities and countries while $33.33 \%$ of this target have chosen the modality "do not know" Only $25.93 \%$ of the parents responded by negation. We must then remember that the principle of mobility as a whole is still not mastered by academic actors. Or, the LMD "is a global system and our University cannot place themselves outside of this event in the West and in other African countries". 


\subsection{The Capitalization}

Just like the legibility and mobility, the principle of capitalisation and transferability of units in the effective implementation of the system LMD is imperative. To check the master or not of this principle, the various respondents were invited to answer the question "The system LMD provide the possibility to the student to change schools without losing its acquired credits?". 59.82\% of Students surveyed on the question of the knowledge of the principle of capitalization recognized that they have no knowledge of this principle of credits in LMD context while $40.18 \%$ said that they have the ability to change schools without losing their acquired credits. As respects to parents, they abounded in the same direction as their child. On this, we note that $38 \%$ have frankly chosen modality 'do not know', 35\% responded in the negative. The rest of the parents (27\%) are aware of the ability of the student to change course without losing its previous achievements. In addition, one of the interviewees resources tried to present the various benefits of the principle of capitalization of knowledge. Thus, he considers the Evaluation credits accumulated and transferred (CECT) as a system which allows to:

[‥] Define a common framework of transparency and comparability of qualifications. There are several benefits including: fostering the mobility of students and teachers between schools at the international level; increase the attractiveness of the African and Malagasy University system with regard to learners, ensure a capitalization of credits, within the course-type of training, and thus encourage resumption of studies; promote links between curriculum; promote the validation of acquired experience or skills more generally; to allow a better definition of the global offer of training from a University (including all skills).

Unfortunately, the issue of accumulated and transferred units remains in ideality while his implementation of the LMD system imposes certain predispositions both infrastructural and human.

\subsection{The Requirements of the LMD System}

The adoption of LMD reform imposes on universities, several necessary conditions for its successful implementation. In this regard and in the context of this research, we have tried to collect some people resources, the information relating to the requirements of the reform to the UAC. The point of views collected are different. In reality, the University, for a better application of the principles of the LMD system must be able to fulfil among others "basic conditions: develop research centres properly equipped; develop enough classroom; recruit enough teachers; build partnerships with other universities and companies; to establish an internet connection for students" has explained a teacher.

Still in the same logic, an administrative authority, more explicitly established the relationship between the requirements of the reform with the various actors of academia.

Thus, he first distinguishes the requirements pertaining to teachers such as: "lead educational projects by generalizing the teamwork of teachers-researchers and researchers, provide the methodology of the academic work, use of ICT (digital libraries, 
E-Learning, MOOC), assess to value taking into account the progress of learner and not to punish the learner". Then, according to the same teacher, this same reform stipule that "The student becomes an active learner; it is no longer passive as in the old system, the learner's personal work is vital and valued, the teacher does not hold only the knowledge "and an" active and ongoing participation in documentary research and scientific investigation (research in digital library, additional courses ...)”. Finally, it presents the requirements relating to the institution that is the University. For him, it must have efficient software, adapted staff, a suitable environment (TIC, WIFI …), track the progress of each learner, and have enough infrastructure (amphi and others …) And recruit enough teachers. Based on this fact, most people approached spoke in reality about the difficulties of UAC in the effective implementation of the LMD system. This is to address the same logic shows that an administrative authority indicate "the conditions that fail to achieve a correct LMD: a stable energy, a correct internet network, each student with a laptop computer, with a possibility of connection permanent. a sufficient number of teachers". It is therefore clear that, not only the infrastructure problem arises with acuity but also those related to human resources including teachers is also very noticeable. Despite these realities the University of Abomey-Calavi facing, we should also note the rigidity of the partnership with the private sector companies as required by the reform. Here, a professional actor confirms this situation by stating that " $[\cdots]$ This partnership remains a problem. It's because of interest that collaboration between business and University, Making it difficult" Concretely, the actors academia of University of Abomey-Calavi confirmed that the university suffers from lack of infrastructure as well as human, material and logistical for effective implementation of the LMD reform.

\section{Conclusions}

The new current context marked by globalization and globalization requires francophone African countries to align with international standards. Thus in the context of higher education, West African countries including Benin Republic gathered in the REESAO have adopted in recent years the LMD system in sight of to respond to the requirements for the internationalization of diplomas, the mobility of students and the professionalization of University training.

Therefore based on fundamental principles, they are still far from mastered and applied by the different actors of the University. In other words, the implementation of the principles of mobility, legibility of diplomas and capitalization of acquired remains rigid because the priority is not given opportunities to promote maximum student success. In sum, to succeed the implementation of the LMD reform, it is urgent to adapt its principles and conditions to endogenous realities given that "[ $\cdots]$ " the LMD is not ready-to-wear because there is not a universal model. At each so its LMD!

\section{References}

[1] Quashie, V. (2009) How Interactive Is the Interactive White-Board? Mathematics Teaching, 214, 33-38. 
[2] Abstract of the Inter-University Seminar of Piloting on the LMD System. Lomé, 10-12 October 2005 .

[3] ADEA et REESAO (2008) Training Guide of LMD for Usage of Institutions of Higher Education of French-Speaking Africa. http://www.ADEAnet.org

[4] Serbanescu-Lestrade (2007) The Implementation of the Bologna Process in France and Germany. Doctoral Thesis, University Paris X Nanterre, Paris.

[5] Houessou, P. (2007) Determinants of Failure at the University of Abomey (Benin): Inventory, Analysis and Perspectives. Mons. Doctoral Thesis. Presses Universitaires de Mons.

[6] Hounmenou, J-C. (2010) The Management of Student Flows by for Enrollment and Validation of the Curriculum. Ben-Géo, 7, 109-117.

[7] Filakota, R. (2008) The Orientation in Higher Education in the Era of the LMD. Communication on the Theme of the Round Table Organized by University Agency of the FrenchSpeaking Countries at the International Day of the French-Speaking Countries, March 20, 2008 in Yaoundé/CAMEROUN: The Academic Orientation Direction and Socio-Professional Insertion/Ministry of Higher Education.

[8] Ayelo, C.J. (2015) Historical and Implementation of the Approach by Skills at the Elementary Level in the Republic of Benin: The New Beninese Advocated to the Kind of Man Educated. Ph.D. in Educational Sciences, University of Abomey-Calavi (UAC), Abomey-Calavi.

[9] Djadji (2003) International Conference on Higher Education: For an University at the Development Service.

[10] Huberman, A.M. (1973) How to Operate the Changes in Education: Contribution to the Study of Innovation. Experience and Innovation in Education No. 4. BIE, Unesco.

[11] Rectorate-UAC (2014) Statistical Yearbook of the 2012-2013 Academic Year. Abomey-Calavi, Rectorate.

[12] Hugon, P. (1970) Integration of African Education in the Development. Tiers-Monde, 11, 17-46. http://dx.doi.org/10.3406/tiers.1970.1682

[13] Ndior, B. (2013) Public Universities in the Test of Professional Studies in the LMD Reform: The Case of Senegal. Doctoral Thesis, Université Starsbourg, Strasbourg.

[14] Krou, A.V. (2012) LMD Reform in Côte d'Ivoire: Implementation and Challenges. General Management of Higher Education, Abidjan.

[15] Rectorate-UAC (2014) Report: Assessment of Academic Management 2012-2014. AbomeyCalavi, Rectorate.

[16] Redriksen, B. (2003) Improvement of Higher Education in Sub-Saharan Africa: What Works! 22-25 September 2003, Accra, Ghana. 
Submit or recommend next manuscript to SCIRP and we will provide best service for you:

Accepting pre-submission inquiries through Email, Facebook, LinkedIn, Twitter, etc. A wide selection of journals (inclusive of 9 subjects, more than 200 journals)

Providing 24-hour high-quality service

User-friendly online submission system

Fair and swift peer-review system

Efficient typesetting and proofreading procedure

Display of the result of downloads and visits, as well as the number of cited articles

Maximum dissemination of your research work

Submit your manuscript at: http://papersubmission.scirp.org/

Or contact jss@scirp.org 